\title{
Cancer on the Testicle Not Descended to the Urology Department of the Gabriel Touré UHC: About a Case
}

\author{
Mamadou Tidiani Coulibaly*, Amadou Berthé, Lahassana dit Tiemoko Coulibaly, Cissé Dramane, \\ Thierno Madane Diop, Issa Amadou, Zanafon Ouattara
}

Urology Department of CHU Gabriel Touré, Bamako, Mali

Email: ^mamadoutc@yahoo.fr

How to cite this paper: Coulibaly, M.T., Berthé, A., dit Tiemoko Coulibaly, L., Dramane, C., Diop, T.M., Amadou, I. and Ouattara, Z. (2018) Cancer on the Testicle Not Descended to the Urology Department of the Gabriel Touré UHC: About a Case. Open Journal of Urology, 8, 257-262. https://doi.org/10.4236/oju.2018.88028

Received: May 28, 2018

Accepted: August 27, 2018

Published: August 30, 2018

Copyright $\odot 2018$ by authors and Scientific Research Publishing Inc. This work is licensed under the Creative Commons Attribution International License (CC BY 4.0).

http://creativecommons.org/licenses/by/4.0/

\begin{abstract}
Testicular cancers are tumours of the young adult (15 - 35 years), and it is a rather rare pathology in African black. However, the risk of developing these cancers becomes higher if the testicle does not descend. In our context, these undescended testicles often go unnoticed, which poses the problem of surveillance. We report a case in a patient of 24 years who consulted for pain plus hypogastric mass, in whom at the end of the clinical, paraclinical and surgical investigations we retained the diagnosis of seminoma of the right testicle. This is the first case in our daily practice. Conclusion: The rarity of tumours on the undescended testicle should not cause their diagnosis to be misunderstood because of the seriousness of cases diagnosed late.
\end{abstract}

\section{Keywords}

Esticle, Cancer, Undescended

\section{Introduction}

Testicular cancer is a cancer of young men and represents about $1 \%$ of all tumours in men. Germinal tumours account for $95 \%$ of testicular cancer cases, the most frequent forms being seminomas (half of cases), mixed non-seminomatous germinal tumours (NGT) and pure embryonic carcinomas [1].

It is an uncommon cancer in black Africans, but the risk of it occurring is very high if the testicle does not descend. These undescended testicles are most often discovered late in our context [1] [2].

This is how we report this case of cancer on the intra-abdominal testicle in 
order to attract the attention of clinicians.

\section{Observation}

M.A.I., 24 years, single without children consulted for mass more hypogastric pain, evolving since one year. It was an episodically evolving pain of varying intensity. During this period the patient was doing traditional treatments without success.

The physical examination in urology revealed a general state little altered, a hypogastric mass (Figure 1), hard, well limited, mobile compared to the superficial and deep plane, a bilateral vacuity of the bursa. This clinical picture made us think of a tumor on the undescended testicles.

The biological examinations were: BHCG: $10 \mathrm{ui} / \mathrm{ml}$; $\alpha$-fetoprotein: 1.16 ui; LDH: 302 ui; ACE: 25 ui.

A CT performed concluded in a hypogastric mass of tissue density with satellite adenomegaly (Figure 2).

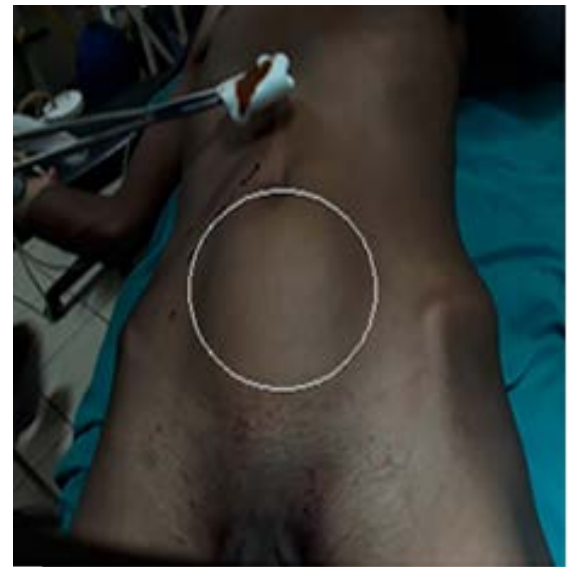

Figure 1. Hypogastric mass.

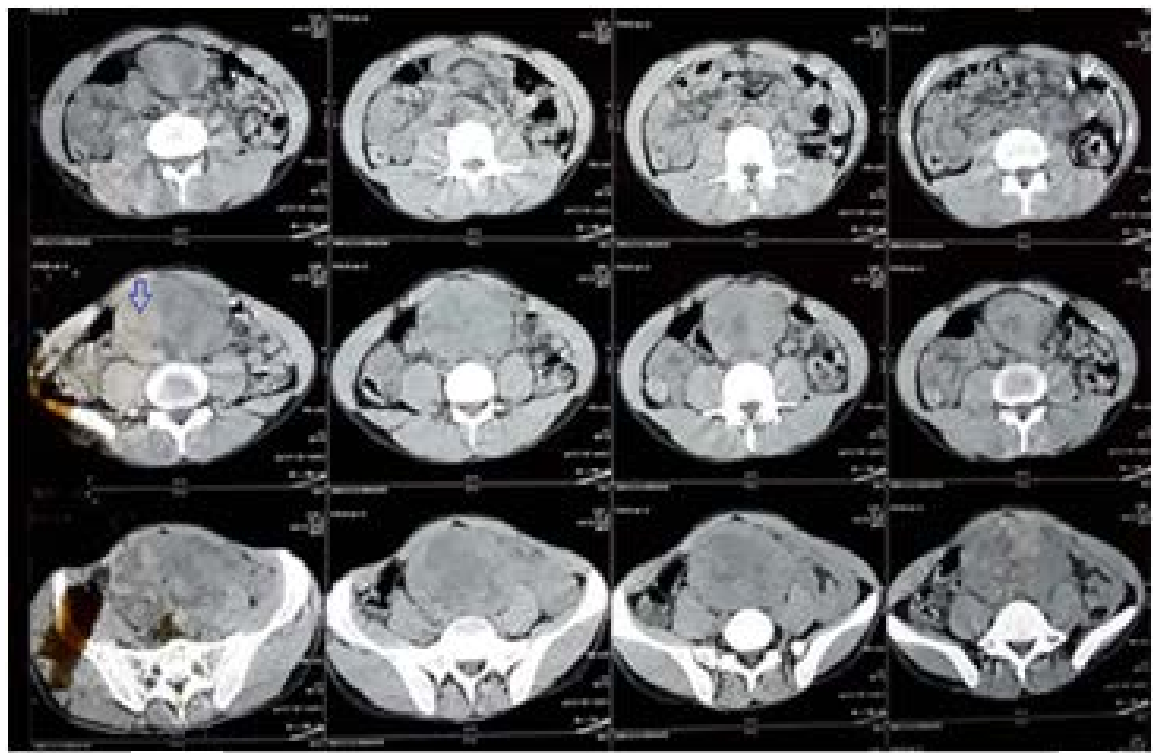

Figure 2. Right testicular tumor on tomodensitometry. 
The surgery performed by a medial incision under the umbilical, objectivized a voluminous tumor of about $17 \times 12 \mathrm{~cm}$ with its spermatic cord well individualized and without visceral adhesion (Figure 3, Figure 4).

We performed a straight orchidectomy, conditioned and sent the specimen to histological examination (Figure 5).

The left testicle was in an intra-abdominal situation and we performed a left orchidectomy (Figure 6).

Anatomopathological examination of the right orchidectomy room revealed a differentiated seminoma.

There were no immediate and short-term postoperative complications. Healing was achieved in 12 days. We have opted for regular monitoring with regard to further care.

\section{Discussion}

At the epidemiological level, the main risk factor for cancer is represented by the

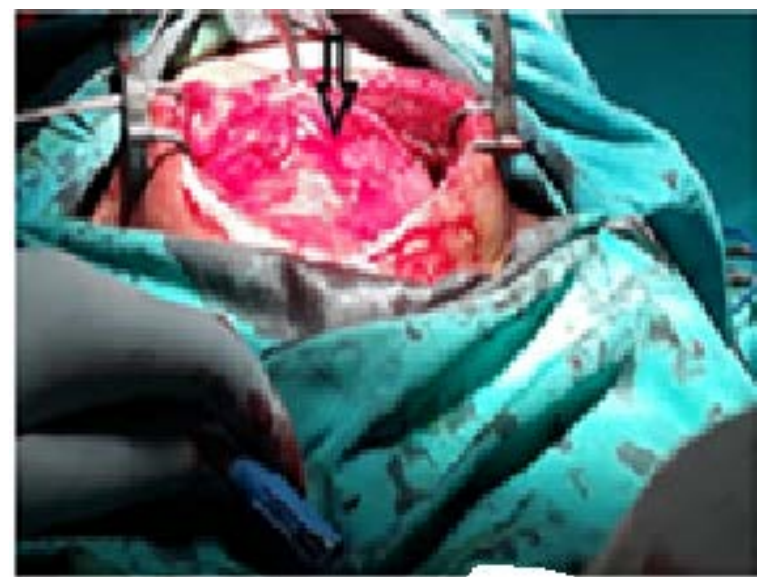

Figure 3. Right testis in intra peritoneal situation.

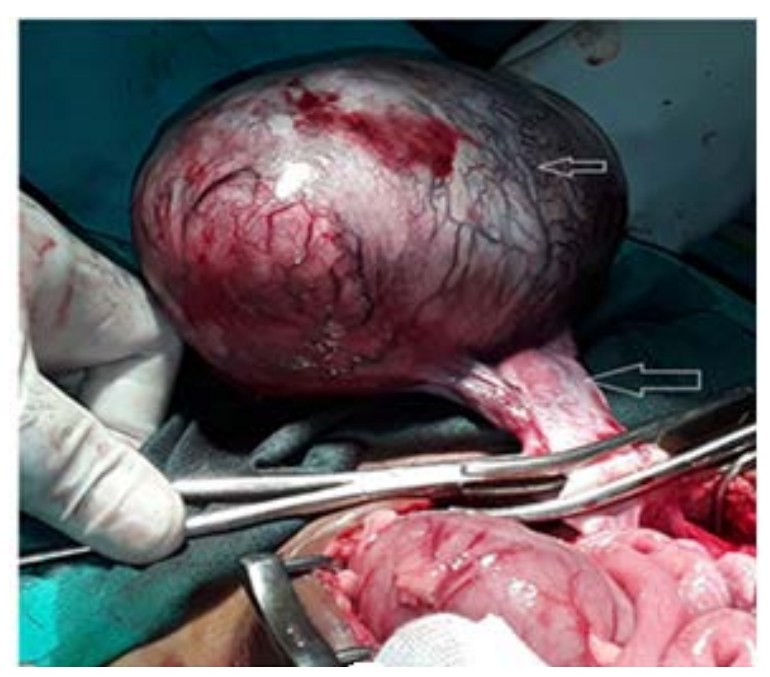

Figure 4. Right testicle with its cord in intra peritoneal situation. 


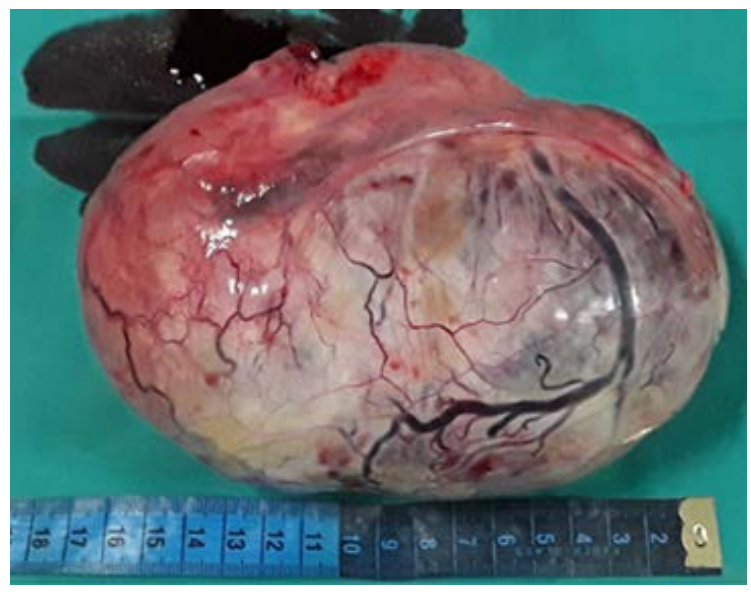

Figure 5. Right testicle after orchidectomy.

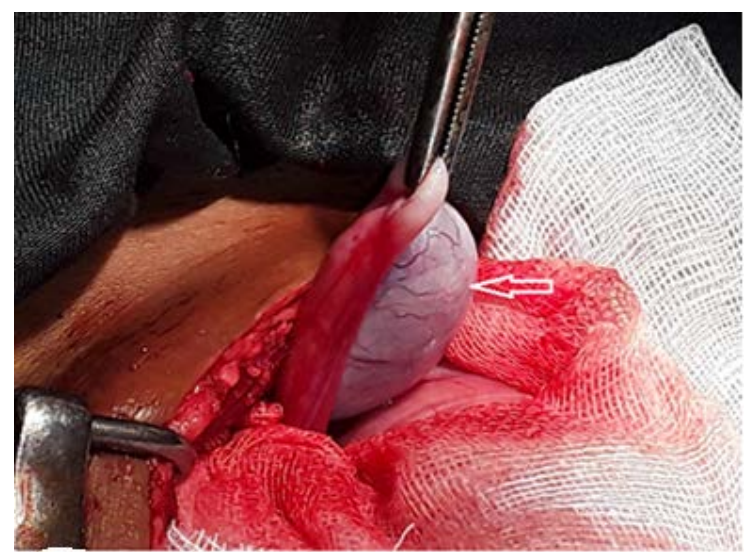

Figure 6. Left testis in intra peritoneal situation.

undescended testicle [1] [2] [3]. According to Campbell, this risk is 48 times greater [4].

Lowering does not prevent cancerization but allows better testicular monitoring.

DEBRE [5] reported $12.5 \%$ cases of tumors on testicle surgically lowered. Biopsies performed at the time of orchidopexy do not predict the chances of subsequent degeneration but rather constitute an additional risk factor. The risk of degeneration would be lower on unbiopsied testis [6].

The level of testicle arrest is also a significant factor because the higher the testicle is located the greater the risk of cancerization [5] [6]. These tumors mainly affect young adults and our patient is no exception, this finding was made in the series of Lamine Niang et al. [7] in Senegal where the average age was 30.6 years.

At the clinical level, the diagnosis was made at the age of 24 in our patient who had a general state little altered. All Niang's patients were at a late stage [7].

Ignorance of scrotal emptiness at birth is said to be the determining factor in delayed diagnosis, as is ignorance among patients who, even as adults, do not consult a doctor for testicular absence.

Other factors come into play: the tumour's intra-abdominal position gives it 
enough space to develop and reach a large volume before becoming symptomatic, misleading symptomatology can also contribute to the delay in diagnosis [7] and in the end, traditional treatment was a significant factor in our patient's diagnosis.

On the histological level, our patient had a seminoma; several studies have shown the predominance of seminomatous tumors in case of cancer on undescended testis.

Coupland [8] studying the risk factors for germlinetumours, concluded that the risk of association between seminoma and undescended testis was significantly greater than that of other tumours (Odds Ratio: 5.3 versus 3.0) and this association would be much greater (Odds Ratio: 11.5 versus 5.1) whenever the patient's age was 32 years or older. However Niang et al. [7] found more embryonic carcinomas than seminomas in their series.

In view of these findings, we can say that cancers on the undescended testis have no histological particularity compared to testicular cancers in the general population.

\section{Conclusions}

Tumours on the undescended testicle are rare; this is the first case in our practice.

This rarity should not cause their seriousness to be ignored because they are diagnosed at an advanced stage which escapes any curative treatment.

The early diagnosis of these tumours requires the lowering of the cryptorchid testicles because even if this lowering does not prevent these tumours, it allows better monitoring.

\section{Conflicts of Interest}

The authors declare no conflicts of interest regarding the publication of this paper.

\section{References}

[1] Abrratt, R.P., Reddi, V.B. and Sarembock, L.A. (1999) Testicular Cancer and Crytorchidism. British Journal of Urology, 70, 656-659. https://doi.org/10.1111/j.1464-410X.1992.tb15838.x

[2] Mottet, N. (2003) Risk Factors for Testicular Cancer and Mechanism of Carcinogenesis. Progrès en Urologie, 13, 1244-1245.

[3] Carmona, C., Regueiro Lopez, J.C., Prieto, C., et al. (2000) Cryptorchidism and Testicular Cancer. Actas Urológicas Españolas, 24, 49-51. https://doi.org/10.1016/S0210-4806(00)72405-3

[4] Campbell, H.E. (1959) The Incidence of Malignant Growth of the Undescended Testicle. A Reply and Reevaluation. Journal of Urology, 81, 663-668. https://doi.org/10.1016/S0022-5347(17)66088-9

[5] Debre, B. (1984) Tumors on the Cryptorchid Testicle. Annales d Urologie, 18, 253-255. 
[6] Swerdlow, A.J., de Stabola, B.L., Swanwick, M.A., et al. (1999) Risk Factors for Testicular Cancer: A Case Control Study in Twins. British Journal of Cancer, 80, 1098-1102.

https://doi.org/10.1038/sj.bjc.6690470

[7] Niang, L., Diao, B., Gueye, S.M., et al. (2007) Cancer on the Testicle Not Descended Intra-Abdominal. About 5 Cases. Progrès en Urologie, 17, 947-949.

https://doi.org/10.1016/S1166-7087(07)92394-5

[8] Coupland, C.A., Chilvers, C.E., Daveyg, et al. (1999) Risk Factors for Testicular Germ Cell Tumors by Histological Tumor Type. British Journal of Cancer, 80, 1859-1863. https://doi.org/10.1038/sj.bjc.6690611 